\title{
What is the role of angiotensin receptor blockers in treatment of hyperuricemia coexisting with arterial hypertension?
}

\author{
Barbara Nieradko-Iwanicka \\ Chair and Department of Hygiene, Medical University of Lublin, Poland
}

\begin{abstract}
Angiotensin receptor blockers or sartans are used to treat arterial hypertension. Hyperuricemia and arterial hypertension often coexist in patients with metabolic syndrome. Also hyperuricemia is correlated with an increased risk of cardiovascular disease and death. There are data suggesting that lowering serum urate may assist in control of arterial hypertension and use of certain drugs for arterial hypertension may reduce the serum uric acid level. The Polish Society of Arterial Hypertension recommends losartan for treatment of arterial hypertension in patients with coexisting hyperuricemia.

The aim of the present review was to find evidence supporting the concept of use and explain the role of sartans in treatment of hyperuricemia.

Thirty-five original and review articles about hyperuricemia and arterial hypertension focusing on the use of sartans in both these medical conditions were analyzed.

In conclusion, sartans should be recommended for treatment of hyperuricemia coexisting with arterial hypertension in patients without bilateral renal artery stenosis and with exclusion of pregnant women.

Key words: hyperuricemia, arterial hypertension, sartans.
\end{abstract}

\section{Introduction}

In humans and higher primates, uric acid (UA) is the final product of purine metabolism. In humans it helps to maintain arterial blood pressure to be high enough to guarantee sufficient blood flow through the brain and distal parts of the body in the erect position. The Western diet, however, is high in purines. In consequence, the serum UA concentration becomes too high. Other mammals produce an enzyme, uricase, which converts UA into allantoin. Humans, primates and Dalmatian dogs lack it, so they are susceptible to hyperuricemia (HU). About $70 \%$ of uric acid is removed from the body with urine and $30 \%$ is removed via the gastrointestinal tract. Hyperuricemia is serum UA concentration $>6 \mathrm{mg} / \mathrm{dl}$ (360 mmol/l). Causes of $\mathrm{HU}$ are under-excretion ( $90 \%$ of cases) and overproduction (10\%).

Hyperuricemia may result from exogenous factors (lifestyle - alcohol overconsumption, diet high in meat, fructose, corn syrup, obesity and use of thiazide diuretics) as well as endogenous (male gender, old age, diabetes mellitus, metabolic syndrome, kidney failure, cardiovascular disease (CVD), arterial hypertension $(\mathrm{AH})$, inflammatory diseases, genetic purine metabolism disorders, stroke and oxidative stress). It is estimated that $30 \%$ of patients with HU have clinical symptoms of gout [1].

According to the American College of Rheumatology (ACR) and European League Against Rheumatism (EULAR), gout is diagnosed if there was an episode of arthritis or bursitis at least once or sodium urate crystals were identified in the joint, bursa or tophus. Clinical symptoms that are taken into consideration are first metatarsophalangeal (MTP) joint, ankle or other MTP except for MTP II involvement, erythema, tenderness, difficulty in walking, minimum 2 typical gout attacks, quick onset of arthritis (< 24 hours), improvement within up to 14 days, remission between attacks, detection of calcium urate deposits in ultrasound or computed

Address for correspondence:

Barbara Nieradko-Iwanicka, Chair and Department of Hygiene, Medical University of Lublin, 11 Radziwiłłowska St, 20-080 Lublin, Poland, e-mail: bnieradkoiwanicka@wp.pl

Submitted: 23.02.2018; Accepted: 30.03.2018 
tomography examination and serum UA concentration $>6 \mathrm{mg} / \mathrm{dl}(360 \mathrm{mmol} / \mathrm{l})[2,3]$.

Hyperuricemia is considered to be an interdisciplinary problem. According to the World Health Organization $\mathrm{HU}$ is a recognized as a risk factor of CVD together with hyperglycemia, insulin resistance, hyperlipidemia, $\mathrm{AH}$, elevated high sensitivity C-reactive protein (hs-CRP) and hyperhomocysteinemia.

At first, HU is asymptomatic. Gout attacks are remittent, with shorter or longer periods with no clinical symptoms. Eventually, chronic arthritis develops in untreated $\mathrm{HU}$. Ultimate control of gout requires control of HU. The UA concentration at the level of 5-6 $\mathrm{mg} / \mathrm{dl}$ prevents recurrent gouty attacks and tophaceous deposits [1, 3-6].

Angiotensin receptor blockers (ARBs) or sartans are widely used to treat $\mathrm{AH}$. Hyperuricemia and $\mathrm{AH}$ often coexist, especially in patients with metabolic syndrome. Hyperuricemia affects 10-15\% of people aged 65-75 and $30-50 \%$ over 85 years of age [7]. In Poland it is estimated that $30 \%$ of the population suffer from arterial hypertension.

There are data suggesting that lowering of SU may assist in control of AH. EULAR and ACR, as well as the $3 e$ initiative, recommend the level of $S U$ to be less than $6 \mathrm{mg} / \mathrm{dl}(360 \mathrm{mmol} / \mathrm{l})$ in uncomplicated $\mathrm{HU}$ and below $5 \mathrm{mg} / \mathrm{dl}(300 \mathrm{mmol} / \mathrm{l})$ in patients with severe gout (with tophi, chronic arthritis, recurrent gout attacks) [3-5]. EULAR does not recommend reducing SU below $3 \mathrm{mg} / \mathrm{dl}$ as there is evidence that SU may play a protective role in prevention of neurodegenerative disorders such as Parkinson's disease, Alzheimer's disease and multiple sclerosis [8-10].

Diuretic drugs used in treatment of $\mathrm{AH}$, however, might increase SU, so they are not recommended for patients with $\mathrm{AH}$ coexisting with HU. The mechanism for diuretic-induced HU may be volume depletion and reduced secretion of UA.

The Polish Society of Arterial Hypertension recommends losartan for treatment of $\mathrm{AH}$ in patients with coexisting HU [11]. Losartan, candesartan, eprosartan, irbesartan, olmesartan, telmisartan and valsartan are ARBs. They block type 1 angiotensin II (AT, R) receptors on blood vessels, but do not inhibit angiotensin converting enzyme (ACE), so they do not cause an increase in bradykinin, which contributes to the vasodilation produced by ACE inhibitors. Therefore ARBs do not cause the side effects of ACE inhibitors such as cough and angioedema [12]. Losartan is exceptional amongst antihypertensive drugs in possessing mild uricosuric properties and therefore has a role in treating patients with $\mathrm{HU}$ and $\mathrm{AH}[11]$.

The mother compounds of sartans have little or no effect on $\mathrm{AH}$, but their metabolites have 10 to 20 times higher clinical efficacy. Their effects are as follows: dilatation of arteries and veins and reduction of arterial pressure, preload and afterload on the heart, down-regulation of the sympathetic adrenergic activity by blocking the effects of angiotensin II on sympathetic nerve release and reuptake of norepinephrine, promotion of renal excretion of sodium and water by blocking the effects of angiotensin $\|$ in the kidney and by blocking angiotensin II stimulation of aldosterone secretion, and inhibition of cardiac and vascular remodeling. However, losartan has the highest potential for interactions with other drugs due to its involvement with the hepatic cytochrome P450 enzyme system [12, 13].

Sartans are contraindicated in pregnancy. All the sartans are pregnancy category $C$ for the first trimester and category D for the second and third trimesters.

Patients with bilateral renal artery stenosis may experience renal failure if sartans are administered. The elevated circulating and intrarenal angiotensin II in this condition constricts the efferent arteriole more than the afferent arteriole within the kidney, which helps to maintain glomerular capillary pressure and filtration. Removing this constriction by blocking angiotensin II receptors on the efferent arteriole causes a rapid fall in glomerular filtration rate $[12,13]$.

The aim of the review was to find evidence supporting the concept of use and explain the role of sartans in treatment of hyperuricemia.

\section{Discussion}

Thirty-five original and review articles about HU and $\mathrm{AH}$ focusing on the use of sartans in both these medical conditions were analyzed.

The treat to target strategy in $\mathrm{HU}$ aims to maintain the serum uric acid level (SU) below $6 \mathrm{mg} / \mathrm{dl}$ over long period of time. Undoubtedly balanced diet and active lifestyle are of key importance in prevention of $\mathrm{HU}$ and gouty attacks. Therefore the patients must be educated by their physician, nurse and consulting rheumatologist [3]. Lowering intake of purines (<200 mg/day), protein, alcohol and fructose containing beverages lowers the level of SU. However, in many patients it is necessary to introduce drugs that alleviate the symptoms of gout attack:

- colchicine (approved by the American Food and Drug Administration [FDA] in 2009) [13] and non-steroidal anti-inflammatory drugs (NSAIDs) or steroids or SU lowering drugs,

- allopurinol and febuxostat, which inhibit UA production via inhibition of xanthine oxidase; febuxostat was approved by the FDA in 2009 [13, 14],

- probenecid or benzbromarone, which have uricosuric properties [7], 
- pegloticase intravenously [15] and rasburicase [16], which neutralize uric acid by conversion to allantoin,

- canakinumab and anakinra, which inhibit interleukin 1 (IL-1) [17].

According to ACR recommendations, treatment of a gout attack should be started immediately within 24 hours after its onset. The drugs of choice are colchicine and NSAIDs or steroids [4]. The mechanism of colchicine action remains unclear, but it is believed that colchicine binds tubulin dimers and may interfere with leucocyte diapedesis, mobilization, degranulation and chemotaxis. Colchicine inhibits caspase 1 and interleukin $1 \beta$ [18-20]. Prophylaxis of gouty attack is recommended in all patients aiming to lower the UA level $<6 \mathrm{mg} / \mathrm{dl}$ (360 mmol/l) with colchicine or NSAIDs. According to the ACR, chronic UA lowering treatment should be conducted in patients with tophi, < 40 years, with UA > $8 \mathrm{mg} / \mathrm{dl}$ (480 mmol/l), after two or more gouty attacks and with coexistence of other diseases such as chronic kidney disease, $\mathrm{AH}$ and heart insufficiency. The drug of choice for them is allopurinol at the dose of $100 \mathrm{mg} /$ day and $50 \mathrm{mg}$ / day in patients with chronic kidney disease stage IV and V; however, allopurinol should be discontinued at a creatinine clearance below $30 \mathrm{ml} / \mathrm{min}$. The dose should be adjusted until UA is $<6 \mathrm{mg} / \mathrm{dl}(360 \mathrm{mmol} / \mathrm{l})$ and symptoms disappear. UA $<5 \mathrm{mg} / \mathrm{dl}(300 \mathrm{mmol} / \mathrm{l})$ should be the therapeutic target in patients with tophi, frequent gout attacks or chronic gouty arthropathy. Patients must be asked if any side effects of allopurinol appeared (itching, elevated transaminases, rash). It is considered reasonable to order genetic testing for HLA-B ${ }^{\star} 5801$ in the Asian population, as a positive result may be connected with an increased risk of allopurinol intolerance [4].

In order to increase the efficacy of $\mathrm{HU}$ treatment, a uricosuric drug may be added. Probenecid is the uricosuric of choice in monotherapy. However, it is contraindicated if eGFR $<50 \mathrm{ml} / \mathrm{min}$. Other drugs of uricosuric properties are fenofibrate used in treatment of dyslipidemia and losartan used in treatment of $\mathrm{AH}$. Before the uricosuric therapy, the uric acid concentration in the urine should be measured. It is also advised to make urine $\mathrm{pH}$ alkaline to prevent formation of kidney stones. The patient should also be interviewed according to the ACR 2012 Checklist for other health problems that increase UA [4, 21, 22].

The $3 e$ initiative in 2014 emphasized that treatment of asymptomatic $\mathrm{HU}$ is not indicated [6].

Treatment with xanthine oxidase inhibitors or uricosuric drugs is recommended in the case of recurrent gout, tophi, gouty arthropathy and/or kidney stones, or if $\mathrm{SU}$ is $>8 \mathrm{mg} / \mathrm{dl}$ and if $\mathrm{HU}$ coexists with chronic kidney disease, $\mathrm{AH}$, or cardiovascular disease [3]. In patients with coexisting $\mathrm{AH}$ and $\mathrm{HU}$, EULAR recommends with- drawal of loop diuretics, if used, and considering the use of losartan or calcium channel blockers. In patients with hyperlipidemia statins or fibrates are recommended [3].

The Polish Society of Arterial Hypertension recommends dihydropyridine calcium channel blockers, angiotensin-converting-enzyme inhibitor (ACEI) and losartan as drugs of choice if $\mathrm{AH}$ coexists with $\mathrm{HU}$ [11]. It is underlined that losartan has uricosuric properties. Thiazide diuretics and beta-blockers are contraindicated. Allopurinol is recommended in patients with $\mathrm{AH}$ with complicated CVD even though HU is symptomless because allopurinol was found to have a positive effect on the aorta and endothelium [11, 23].

Hyperuricemia is correlated with an increased risk of cardiovascular disease (CVD) and risk of death. It is known that $\mathrm{HU}$ in patients with $\mathrm{AH}$ leads to inflammation, proliferation of smooth muscle cells in the walls of blood vessels [24], oxidative stress [25], activation of the renin-angiotensin system [26], endothelial disruption, reduced NO production, increased gluconeogenesis, reduced insulin production, reduced synthesis of adiponectin [27], increased lipid production, accumulation of triglycerides in the blood [28], reduced oxidation of fatty acids and arteriosclerosis in consequence [26].

Uric acid stimulates proliferative pathways in vascular smooth muscle cells via induction of platelet-derived growth factor receptor $\beta$ (PDGFR $\beta$ ) phosphorylation, which plays a crucial role in the development of CVD, and the elevated UA levels could be a potential therapeutic target in patients with CVD [24].

Uric acid upregulates both the renin-angiotensin-aldosterone system (RAA system) - angiotensinogen (AGT), ACE1, renin, $A T_{1} R$, angiotensin type 2 receptor $\left(A T_{2} R\right)$ mRNA expression - and angiotensin II protein secretion and causes a significant increase in intracellular reactive oxygen species (ROS) production in 3T3-L1 adipocytes. These effects could be prevented by RAS inhibitors such as losartan. RAS activation has been causally implicated in oxidative stress induced by uric acid in 3T3-L1 adipocytes, suggesting a plausible mechanism through which HU contributes to the pathogenesis of obesity-related CVD [26].

There have been numerous clinical trials with patients with coexisting $\mathrm{AH}$ and $\mathrm{HU}$ indicating the positive effect of sartans. However, according to Motozato et al. not all the sartans are equal. The authors stated that a single-pill fixed-dose combination therapy with irbesartan $100 \mathrm{mg}$ per day and amlodipine $5 \mathrm{mg} /$ day is superior to the combination of valsartan $80 \mathrm{mg}$ per day and amlodipine $5 \mathrm{mg}$ per day with respect to significant decreases in blood pressure (BP) and serum UA in patients with $\mathrm{AH}[28]$. 
In another study conducted by Ueno et al. [22] 751 patients with $\mathrm{AH}$ were treated with diuretics, $\beta$-blockers or $\alpha$ - 1 blockers. The eGFR in patients treated with these drugs was negatively correlated with UA level. The drugs reduced eGFR and raised UA levels. Calcium channel blockers, ACE inhibitors and ARBs, including losartan, did not increase serum UA levels [22].

In the study of Chida et al. [29] a total of 40 highrisk $\mathrm{AH}$ patients with coronary artery disease, CVD and/ or diabetes complications who were taking ARBs other than irbesartan and losartan were enrolled in the study. After a 4-week control period, the patients' prescribed ARBs were exchanged for an equivalent dose of irbesartan. The UA level dropped from $5.9 \pm 1.6$ to $5.5 \pm 1.6 \mathrm{mg}$ / $\mathrm{dl}(p=0.028)$ and levels of the oxidative stress marker derivative reactive oxygen metabolites were significantly lower at 12 weeks of treatment compared with before treatment. These results suggest that irbesartan has beneficial effects on $\mathrm{HU}$ and oxidative stress [29].

Ishimitsu et al. [30] conducted a prospective clinical survey examining the efficacy and safety of 12 -week treatment with amlodipine and an ARB in 5900 patients with $\mathrm{AH}$. The combination antihypertensive therapy with amlodipine and ARB effectively lowered blood pressure and reduced SU [30].

In a metaanalysis published by Fan et al. [31] randomized controlled trials regarding losartan treatment for $\mathrm{AH}$ patients with $\mathrm{HU}$ in China with 2754 patients were analyzed. Losartan significantly reduced serum UA compared with other antihypertensive agents. Losartan did not produce cough as a side effect, unlike ACEIs [31].

In a study conducted by Pérez Carreño et al. [32] 99 patients with $\mathrm{AH}$ and $\mathrm{HU}$ received amlodipine at the dose of $5 \mathrm{mg}$ and losartan at the dose of $50 \mathrm{mg}$ or $100 \mathrm{mg}$ according to their baseline BP. The secondary outcomes were changes in BP, serum UA and albuminuria from baseline. After 6 months there were 64 (95\%) patients with adequately controlled $\mathrm{AH}$. Every two of three patients reached adequate control of $\mathrm{AH}$ and $\mathrm{HU}$ after 6 months of combined antihypertensive treatment with amlodipine and losartan [32].

Hosoya et al. [33] evaluated the effect of losartan at the dose of $50 \mathrm{mg}$ plus $12.5 \mathrm{mg}$ hydrochlorothiazide for achieving better BP control in 164 patients. The study had a sub-analysis focusing on the effect of the drugs on the serum UA. The authors indicated that losartan with hydrochlorothiazide effectively lowered UA in patients' blood sera [33, 34].

Some general practitioners doubt the possibility of patient compliance when treated long term with sartans as they should be taken twice daily. However, the evidence in the United Kingdom General Practice Research Database, which involved 109454 patients with $\mathrm{AH}$, is against this argument. Within 10 years of observation the treatment was interrupted 223228 times. The best compliance was recorded in patients treated with sartans [35].

Also experiments on animals were conducted in order to prove sartans' effectiveness in lowering serum UA and metabolism improvement. The study conducted by Sahataa et al. [27] was designed to assess the effect of telmisartan and pioglitazone on high fructose induced metabolic syndrome. Male albino rats received telmisar$\tan$ at the dose of $5 \mathrm{mg} / \mathrm{kg}$, or pioglitazone at the dose of $10 \mathrm{mg} / \mathrm{kg}$, or telmisartan and pioglitazone. Combined telmisartan and pioglitazone allowed better control of $\mathrm{BP}$, hyperglycemia, $\mathrm{HU}$, insulin resistance, and the amelioration of body mass increase [27].

Zheng et al. [26] aimed to investigate the mechanisms underlying the therapeutic effects of losartan on $\mathrm{HU}$-induced aortic atherosclerosis, in an experimental rabbit model. Male rabbits with $\mathrm{HU}$ and hypercholesterolemia were treated with losartan at the dose of $30 \mathrm{mg} / \mathrm{kg}$ per day. Serum UA and plasma renin and angiotensin II activities were determined. Intima thickness was also assessed. After 12 weeks of treatment in the group with $\mathrm{HU}$ treated with losartan plasma renin activity was not different from baseline and UA concentrations as well as plasma angiotensin II activity were moderately enhanced. The group treated with losartan had reduced intima thickness compared to controls. The authors concluded that losartan could alleviate experimental atherosclerosis induced by HU [26].

\section{Conclusions}

Hyperuricemia is correlated with an increased risk of cardiovascular disease CVD and risk of death. Losartan is exceptional amongst antihypertensive drugs in possessing mild uricosuric properties. However, losartan has the highest potential for interactions with other drugs due to its involvement with the hepatic cytochrome P450 enzyme system.

Sartans should be recommended for treatment of $\mathrm{HU}$ coexisting with $\mathrm{AH}$ in patients without bilateral renal artery stenosis and non-pregnant women.

The author declares no conflict of interest.

\section{References}

1. Widecka K, Szymański FM, Filipiak KJ, et al. Stanowisko ekspertów dotyczące hiperurykemii i jej leczenia u pacjentów z wysokim ryzykiem sercowo-naczyniowym. Arter Hypertens 2017; 21: 1-9.

2. Neogi T, Jansen K, Dalbeth N. 2015 gout classification criteria: an American College of Rheumatology/European League 
Against Rheumatism collaborate initiative. Ann Rheum Dis 2015; 74: 1789-1798.

3. Richette P, Doherty M, Pascual E, et al. 2016 updated EULAR evidence-based recommendations for the management of gout. Ann Rheum Dis 2017; 76: 29-42.

4. Khanna D, Fitzgerald JD, Khanna PP, et al. American College of Rheumatology 2012 American College of Rheumatology guidelines for management of gout. Part 1: systematic nonpharmacologic and pharmacologic therapeutic approaches to hyperuricemia. Arthritis Care Res 2012; 64: 1431-1446.

5. Swarowska-Knap J. Dna moczanowa - współczesny problem kliniczny. Medycyna po Dyplomie 2017; 1: 51-56.

6. Sivera F, Andres M, Carmona L, et al. Multinational evidence-based recommendations for the diagnosis and management of gout: integrating systematic literature review and expert opinion of a broad panel of rheumatologists in the $3 e$ initiative. Ann Rheum Dis 2014; 73: 328-335.

7. Fauci AS. Rheumatology. $3^{\text {rd }}$ ed. McGraw Hill Education 2013.

8. Peng F, Zhanf B, Zhong X, et al. Serum uric acid levels of patients with multiple sclerosis and other neurological diseases. Mult Scler 2008; 14: 188-196.

9. Chamarro A, Amaro S, Castellanos M, et al. Safety and efficacy of uric acid in pastients with acute stroke (URICO-ICUS): a randomised, double blind phase $2 b / 3$ trial. Lancet Neurol 2014; 13: 453-460.

10. Schretlen DJ, Inscore AB, Vannordsdall D, et al. Serum uric acid and brain ischemia in normal elderly adults. Neurology 2007 69: 1418-1423.

11. Tykarski A, Widecka K, Filipiak KJ. Zasady postępowania w nadciśnieniu tętniczym - 2015 rok. Wytyczne Polskiego Towarzystwa Nadciśnienia Tętniczego. Próba komentarza na temat ich zasadności. Nadciśnienie Tętnicze w Praktyce 2015; 1: 71-94.

12. Barreras A, Gurk-Turner C. Angiotensin II receptor blockers. Proc Bayl Univ Med Cent 2003; 16: 123-126.

13. Rodgers JE, Patterson JH. Angiotensin II-receptor blockers: clinical relevance and therapeutic role. Am J Health Syst Pharm 2001; 58: 671-683.

14. Schlesinger A. New agents for the treatment of gout and hyperuricemia: febuxostat, puricase and beyond. Curr Rheum Rep 2010; 12: 130-134.

15. Sundy JS, Baraf HS, Becker MA, et al. Efficacy and safety of intravenous (IV) pegloticase (PGL) in sublects with treatment failure gout (FG): phase 3 results from GOU1 and GOU2. Arthritis Rheum 2008; 58: S635.

16. Goldman SC, Holcenberg JS, Finkelstein JZ, et al. A randomized comparison between rasburicase and allopurinol in children with lymphoma or leukemia at high risk for tumor lysis. Blood 2001; 97: 2998-3003.

17. Li S, Yang H, Guo Y, et al. Comparative efficacy and safety of urate-lowering therapy for the treatment of hyperuricemia: a systemic review and network meta-analysis. Sci Rep 2016; 6: 33-82.

18. Basic and clinical pharmacology. Katzung BG (ed.). $6^{\text {th }}$ ed. Appleton \& Lange, Norwalk 1995: 536-559.

19. Martinon F, Petrilli V, Mayor A, et al. Gout-associated uric acid crystals activate the NALP3 inflammasome. Nature 2006; 440 237-241.

20. Terkeltaub B, Furst DE, Bennett K, et al. Colchicine efficacy assessed by time to $50 \%$ reduction of pain is comparable in low dose and high dose regimens: secondary analyses of the AGREE trial. Arthritis Rheum 2009; 59: S1108.

21. Rubio-Guerra AF, Garro-Almendaro AK, Elizalde-Barrera $\mathrm{Cl}$, et al. Effect of losartan combined with amlodipine or with a thiazide on uric acid levels in hypertensive patients. Ther Adv Cardiovasc Dis 2017; 11: 57-62.

22. Ueno S, Hamada T, Taniguchi S, et al. Effect of Antihypertensive Drugs on Uric Acid Metabolism in Patients with Hypertension: Cross-Sectional Cohort Study. Drug Res 2016; 66: 628-632.

23. Tykarski A, Narkiewicz K, Gaciong Z, et al. Zasady postepowania w nadciśnieniu tętniczym - 2015 rok. Nadciśnienie Tętnicze w Praktyce 2015; 1: 1-70.

24. Kýrça M, Ođuz N, Çetin A, et al. Uric acid stimulates proliferative pathways in vascular smooth muscle cells through the activation of p38 MAPK, p44/42 MAPK and PDGFR $\beta$. J Recept Signal Transduct Res 2017; 37: 167-173.

25. Zhang JX, Zhang YP, Wu QN, et al. Uric acid induces oxidative stress via an activation of the renin-angiotensin system in 3T3-L1 adipocytes. Endocrine 2015; 48: 135-142.

26. Zheng H, Li N, Ding Y, et al. Losartan alleviates hyperuricemia-induced atherosclerosis in a rabbit model. Int J Clin Exp Pathol 2015; 8: 10428-10435.

27. Shahataa MG, Mostafa-Hedeab G, Ali EF, et al. Effects of telmisartan and pioglitazone on high fructose induced metabolic syndrome in rats. Can J Physiol Pharmacol 2016; 94: 907-917.

28. Motozato K, Miura S, Shiga Y, et al. Efficacy and safety of two single-pill fixed-dose combinations of angiotensin II receptor blockers/calcium channel blockers in hypertensive patients (EXAMINER study). Clin Exp Hypertens 2016; 38: 45-50.

29. Chida R, Hisauchi I, Toyoda S, et al. Impact of irbesartan, an angiotensin receptor blocker, on uric acid level and oxidative stress in high-risk hypertension patients. Hypertens Res 2015; 38: 765-769.

30. Ishimitsu T, Fukuda $H$, Uchida $M$, et al. The therapeutic advantage of combination antihypertensive drug therapy using amlodipine and irbesartan in hypertensive patients: Analysis of the post-marketing survey data from PARTNER (Practical combination therapy of Amlodin and angiotensin II Receptor blocker; safety and efficacy in patients with hypertension) study. Clin Exp Hypertens 2015; 37: 542-550.

31. Fan Y, Wei F, Lang Y, et al. Losartan treatment for hypertensive patients with hyperuricemia in Chinese population: a metaanalysis. J Hypertens 2015; 33: 681-688.

32. Pérez Carreño JG, Romero JD, Villar Centeno JC. METAL Study Investigators. Echocardiographic changes and treatment goal rates after a 6-month combined treatment with amlodipine and losartan: a validation study in Andean countries (METAL study). Ther Adv Cardiovasc Dis 2013; 7: 237-245.

33. Hosoya T, Kuriyama S, Yoshizawa T, et al. Effects of combined antihypertensive therapy with losartan/hydrochlorothiazide on uric acid metabolism. Intern Med 2012; 51: 2509-2514.

34. Hosoya T, Kuriyama S, Ohno I, et al. Antihypertensive effect of a fixed-dose combination of losartan/hydrochlorothiazide in patients with uncontrolled hypertension: a multicenter study. Clin Exp Nephrol 2012; 16: 269-278.

35. Rycombel A, Lomper K, Uchmanowicz I. Adherence i compliance $w$ leczeniu nadciśnienia tętniczego. Nadciśnienie Tętnicze 2014; 18: 151-158. 